Research Article

\title{
MECHANICAL PROPERTIES OF COMPOSITE PLATES AT DIFFERENT CONDITIONS
}

\section{Gurbet ÖRÇEN ${ }^{I^{*}}$, Kadir TURAN ${ }^{2}$, Sedat BINGGÖL $L^{3}$}

In this study; the effects of thermal aging on the mechanical properties of composite materials were investigated. In study, eight layered woven glass fiber reinforced epoxy composite plates were used. Thermal aging was performed in an electric furnace using time and temperature change parameters. The time changes were 1,3 and 5 hours, and $50{ }^{\circ} \mathrm{C}, 100{ }^{\circ} \mathrm{C}$, and $150{ }^{\circ} \mathrm{C}$ were used for temperature changes. Thermally aged composite plates, at specified time and temperature values; modulus of elasticity, poisson ratio, tensile strength, compression strength, shear modulus and shear strength were determined in fiber reinforcement direction. The results obtained were compared with the results obtained from the specimens waited at room temperature. At the end of the study, it was determined that the mechanical properties of the composite plates changed when the thermal aging temperature and temperature increased.

Key words: Thermal Aged, Composite Plates, Mechanical Properties, Environmental Effects.

\section{Introduction}

The need for materials with advanced mechanical properties is now met by using composite materials. One of the most important features of composite materials is that they can be designed. The design requires that the loads and temperatures at which the product is used be predetermined. This is not the case for composite materials, although it has been identified for conventional materials. In this meaning, the effect of thermal aging on mechanical behavior requires a good analysis and appropriate design.

Many studies have been conducted in the literature, especially on the effects of thermal aging on composite plates. Mouzakis et al. [1] investigated the damage behavior of glass fiber / polyester composite materials exposed to different environmental conditions. They studied changes in ambient temperature, humidity and UV radiation on mechanical properties. In the study, they determined that the tensile strength of the specimens decreased by $2.5 \%$, the modulus of elasticity increased by $7 \%$ and the elongation rate increased by $13 \%$. Leveque et al. [2] investigated the effects of thermal aging on the strength and mechanical behavior of polymer matrix composites. In the study, they stated that the mechanical properties of carbon epoxy composites with different reinforcement angles changed

\footnotetext{
1 Department of Mechanical Engineering, University of Dicle, Diyarbakır, Turkey, (gurbetorcen@dicle.edu.tr) https://orcid.org/0000-0002-8329-8142

2 Department of Mechanical Engineering, University of Dicle, Diyarbakır, Turkey, (kturan@dicle.edu.tr) (Dhttps://orcid.org/00000002-4065-9649

3 Department of Mechanical Engineering, University of Dicle, Diyarbakır, Turkey, (sbingol@ dicle.edu.tr) (Dhttps://orcid.org/00000002-4290-4193
} 
when exposed to thermal aging under a constant temperature of $120{ }^{\circ} \mathrm{C}$ in the range of 720 to 4400 hours. Ktsotsi et al. [3] investigated the mechanical behavior of aged carbon/epoxy composite sheets at different pressures and temperatures. They determined that the aging process affects mechanical behavior. Mulina et al. [4] examined the effects of glass fiber/vinylester and glass fiber/epoxy composite sheets on thermo-mechanical properties. As a result of the study, they determined that the creep elongation increases due to the increase in temperature. Alcock et al. [5] investigated changes in the mechanical performance of polypropylene tapes exposed to different temperatures. They found that increasing temperatures adversely affect tensile strength. Brinson and Gates [6] investigated the effects of thermal aging on the creep behavior of polymer matrix composites. Specifically, they determined that temperatures above glass transition temperatures adversely affect mechanical behavior. Dlouhy et al. [7] investigated the effects of thermal aging on fracture toughness and mechanical properties of glass matrix composite sheets reinforced with short carbon fibers. They found that the thermal aging process reduced the tensile strength by $44 \%$ to $77 \%$ and that the fracture toughness of the samples aged at $700{ }^{\circ} \mathrm{C}$ decreased by $84 \%$. Ray [8], investigated the effects of thermal shock on the interface shear stresses of glass fiber/epoxy composite plates. They calculated that interfacial shear strength decreased for 5 minutes and increased for later periods. Hu and Sun [9], investigated the creep behavior of carbon/epoxy composite plates exposed to thermal aging at certain times. Belaid et al. [10] investigated the effects of thermal aging on the mechanical behavior of glass fiber / polyester composite plates. They stated that as time increases, modulus of elasticity decreases by approximately $50 \%$ and tensile strength decreases by $22 \%$. Cao et al. $[11,12]$ investigated the effect of temperature on carbon fiber reinforced polymer (CFRP) layered, hybrid carbon/glass fiber reinforced polymer layered (C/GFRP), hybrid carbon / basalt fiber reinforced polymer layered (C/ BFRP) composites. The authors stated that carbon fibers containing different fiber-reinforced polymer layers significantly decreased their tensile strength with increasing temperature. However, it is stated that the tensile strength of FRP sheets is still a constant value after reaching the polymer glass transition temperature ( $\mathrm{Tg}$ ) and this value is higher than the tensile strength of the impregnated fiber sheets [12]. Sauder et al. [13] measured the fundamental mechanical properties of various carbon fibers up to $2400{ }^{\circ} \mathrm{C}$ by tensile testing. In this study, it was stated that Young's modulus decreased with increasing temperature and tensile strength increased to a maximum value. Nikolaev et al. [14] investigated the effect of temperature on stationary and cycles ranging from $120{ }^{\circ} \mathrm{C}$ to $196{ }^{\circ} \mathrm{C}$ on CFRP-produced samples. Giannadakis and Varna [15] investigated the effect of thermal fatigue and thermal aging on CF/EP composites. The authors stated that the mechanical properties of specimens exposed to thermal aging over long periods of time decreased mainly as a result of matrix degradation. Eric et al. [16], investigated the changes in the mechanical properties of porous-Matrix Ceramic composites which were kept at $1000{ }^{\circ} \mathrm{C}, 1100{ }^{\circ} \mathrm{C}, 1200{ }^{\circ} \mathrm{C}$ for 1000 hours. $\left[0^{\circ} / 90^{\circ}\right]$ composite, 1200 ${ }^{0} \mathrm{C}$ after heat treatment; they stated that the value of $60 \mathrm{GPa}$ increased to $70 \mathrm{GPa}$, thus increasing the modulus of elasticity with a small increase. Plecnik [17] investigated the strength of epoxy resin at elevated temperatures by performing compression, tensile and shear tests. They stated that the strength decreased at temperatures close to the glass transition temperature and reached a fixed value when the glass transition temperature was exceeded. Rami et al. [18] investigated the mechanical properties of carbon, glass and glass-carbon hybrid composite plates under different temperatures. They stated that the tensile strength and elastic modulus value of carbon, glass and carbon-glass hybrid composite decreased when the temperature was increased. 
This study; it is important to observe the effects of temperature and time changes on the mechanical properties of composite plates. For this purpose, in order to clearly observe the effects and changes of temperature change and time change, the test results of thermally aged specimens were compared with the results of samples waited at room temperature $\left(25^{\circ} \mathrm{C}\right)$. Mechanical properties obtained in fiber reinforcement direction were investigated. The change of these mechanical properties is an important area in terms of reconsidering the convenient design conditions with reference to temperature and time changes of the composites.

\section{Experimental Study}

In this study, the tests on glass fiber reinforced epoxy composite plates were divided into three groups. In group 1; Tensile tests were performed to determine modulus of elasticity, tensile strength and poisson ratio. In 2rd group, compression tests were performed. In the 3rd group, tests were performed to determine the shear modulus and shear failure load. Specimens were prepared from 1.6 mm thick composite plate according to ASTM standards. The prepared specimens were subjected to thermal aging at $50{ }^{\circ} \mathrm{C}, 100{ }^{\circ} \mathrm{C}, 150{ }^{\circ} \mathrm{C}$ for 1 hour, 3 hours and 5 hours in an electric oven where ambient humidity was neglected. For the consistency of the experimental study, three samples were produced for each parameter and experiment. The specimens were allowed to cool after being removed from the furnace and tested after cooling. The arithmetic mean of the obtained results were taken and transferred to tables and graphs.

\subsection{Tensile Test}

Elasticity modulus ( $\left.\mathrm{E}_{11}\right)$, poisson ratio and tensile strength were determined by tensile tests in the direction of fiber reinforcement. Strain gauges were used to determine the modulus of elasticity and poisson ratio. Specimens were used $14 \mathrm{~mm}$ width, $200 \mathrm{~mm}$ length and $1 \mathrm{~mm}$ thickness and $0^{\circ}$ fiber reinforcement angle. Since woven glass fiber is used, the mechanical properties parallel to the fiber reinforcement direction and perpendicular to the fiber reinforcement are equal.

Modulus of elasticity and poisson ratio were determined according to ASTM D3039-76 standard [19]. Specimens were tested in the tensile device at a rate of $1 \mathrm{~mm} / \mathrm{min}$. The axial normal tension of the specimens in the fiber direction $\left(\sigma_{11}\right)$ was obtained by dividing the tensile load $(\mathrm{F})$ by the cross-sectional area (A). The elongation values in the fiber reinforcement direction $\left(\varepsilon_{11}\right)$ were determined by the values obtained from the strain-gauge. The modulus of elasticity $\left(\mathrm{E}_{11}\right)$ in the fiber reinforcement direction was calculated by substituting the obtained values in the formula (1).

$$
\sigma_{11}=\frac{\mathrm{F}}{\mathrm{A}} ; \varepsilon_{11}=\frac{\Delta \mathrm{l}}{\mathrm{l}}=>\mathrm{E}_{11}=\frac{\sigma_{11}}{\varepsilon_{11}}(\mathrm{MPa})
$$

To determine the Poisson ratio, strain gauge was used to calculate the transverse shrinkage ratio perpendicular to the fiber $\left(\varepsilon_{22}\right)$. The poisson ratio was also determined using the formula (2).

$$
\vartheta_{12}=-\frac{\varepsilon_{22}}{\varepsilon_{11}}
$$

In the determination of the tensile failure load, the tensile load is increased until the specimens breaks. The tensile damage load in the fiber reinforcement direction was determined by the formula (3) by dividing the obtained maximum load (Pult), into the cross-sectional area (A). 


$$
X_{t}=\frac{P_{u l t}}{A}(M P a)
$$

In tensile test, three specimens were made from each geometry and load-extension graphs were obtained by using the data obtained from these specimens. Figure 1 presents the results obtained from specimens waiting at $100^{\circ} \mathrm{C}$ for 1 hour.

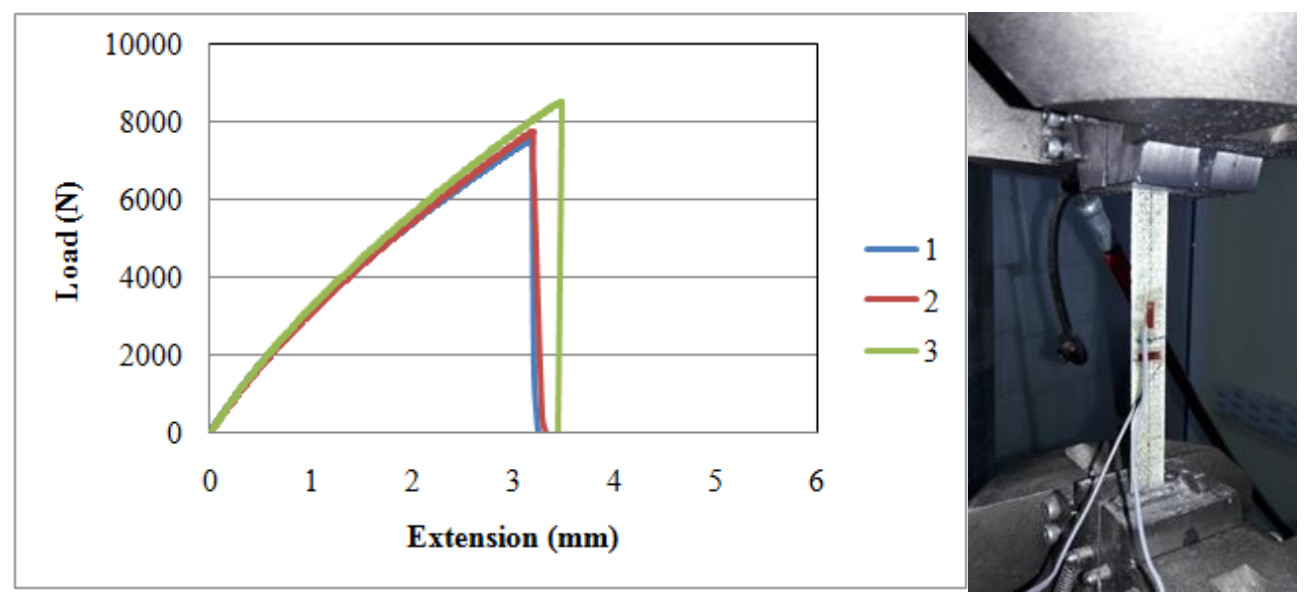

Figure 1. Tensile test set of and tensile test results of three specimens thermal aging for 1 hour at $100^{\circ} \mathrm{C}$.

\subsection{Compression Test}

The specimens whose geometry is specified in Figure 2 for determination of compression failure load were prepared according to ASTM 3410-75 [19]. The test was carried out by increasing the compressive load until the specimens were broken.

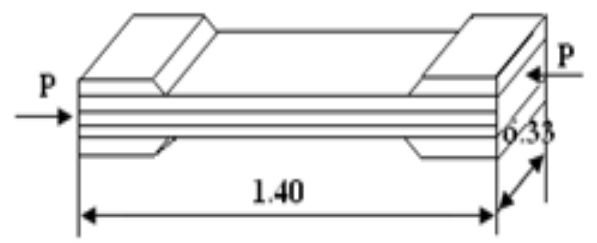

Figure 2. The geometry of the test specimen prepared for the determination of compressive strength [20].

The compressive strength is obtained by the formula 4 , that is, by dividing the maximum compressive failure load $\left(\mathrm{P}_{\text {ult }}\right)$ by the cross-sectional area $(\mathrm{A})$.

$X_{c}=\frac{P_{u l t}}{A}(M P a)$

In Figure 3, the load-extension graph of three specimens prepared at $100^{\circ} \mathrm{C}$ for 1 hour is given as an example. 

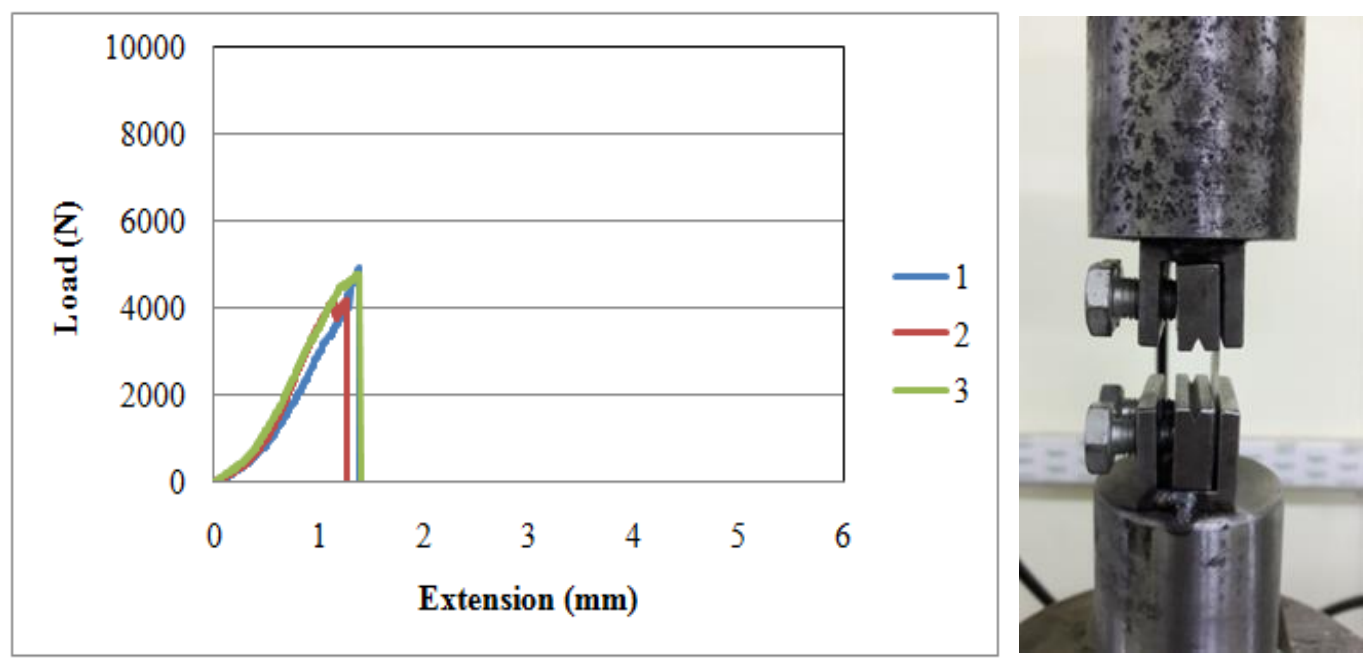

Figure 3. Results of compression test and compression test set of thermally aged sample for 1 hour at $100{ }^{\circ} \mathrm{C}$.

\subsection{Shear Test}

Specimens were prepared according to ASTM 5379 standard [19] to determine the shear modulus and shear failure load. The specimen geometry shown in Figure 4 was used in the shear test.

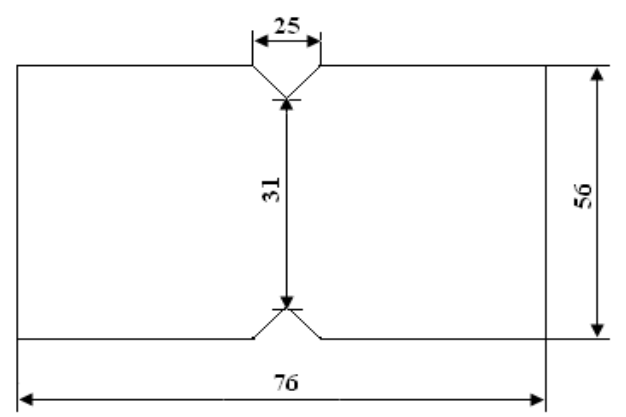

Figure 4. Specimens geometry for shear testing [20].

The shear failure load $\left(\mathrm{S}_{12}\right)$ was calculated by the formula (5) and the shear modulus $\left(\mathrm{G}_{12}\right)$ was calculated by the formula (6) from the linear region of the graph indicated in Figure 5.

$$
\begin{gathered}
S_{12}=\tau=\frac{p_{\text {ort }}}{A} \\
G_{12}=\frac{P}{2 \cdot A \cdot \varepsilon}
\end{gathered}
$$

In Figure 5, the load-extansion graph of the three specimens prepared for 1 hour at $100{ }^{\circ} \mathrm{C}$ is given as an example. 

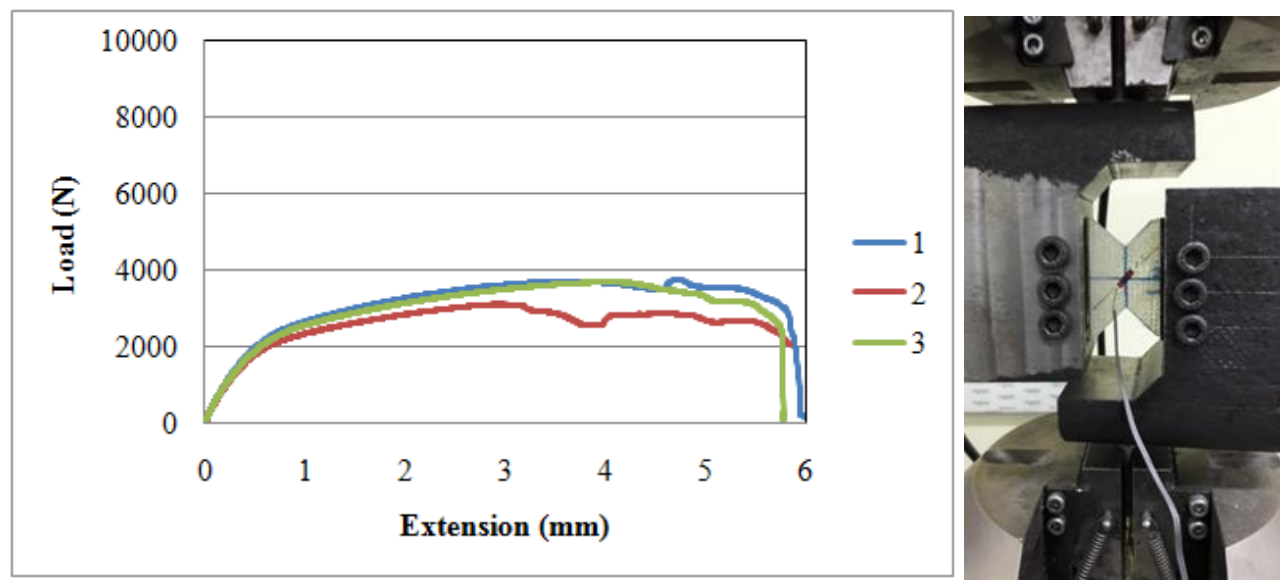

Figure 5. Shear test results and shear test set of thermally aged specimens for 1 hour at $100{ }^{\circ} \mathrm{C}$.

\section{Experimental results and discussion}

\subsection{The effect of thermal temperature on strength and comparison}

For the determination of tensile strength of glass fiber reinforced epoxy composite specimens, the values obtained from the test results were averaged and transferred to Figure 6 and Table 1.

When Figure 6 and Table 1 are examined; it is seen that the tensile strength values obtained at $50{ }^{\circ} \mathrm{C}$, $100{ }^{\circ} \mathrm{C}$ and $150{ }^{\circ} \mathrm{C}$ are actually close to each other, but these values are higher than those obtained from specimens kept at room temperature $\left(25^{\circ} \mathrm{C}\right)$. It is seen that the temperature has an increasing effect on the tensile strength of the composite material, but it decreases as the waiting time increases. While it reaches maximum value at $100{ }^{\circ} \mathrm{C}$ for all three waiting dwell times, it is seen that these values decrease at $150{ }^{\circ} \mathrm{C}$ and close values are obtained. It was found that the tensile strength of the specimens which was kept at $150{ }^{\circ} \mathrm{C}$ for 1 hour increased by $9.58 \%$ compared to the value obtained from the specimens kept at room temperature, and decreased by $6.35 \%$ according to the value obtained from specimens kept at $100{ }^{\circ} \mathrm{C}$ for 1 hour.
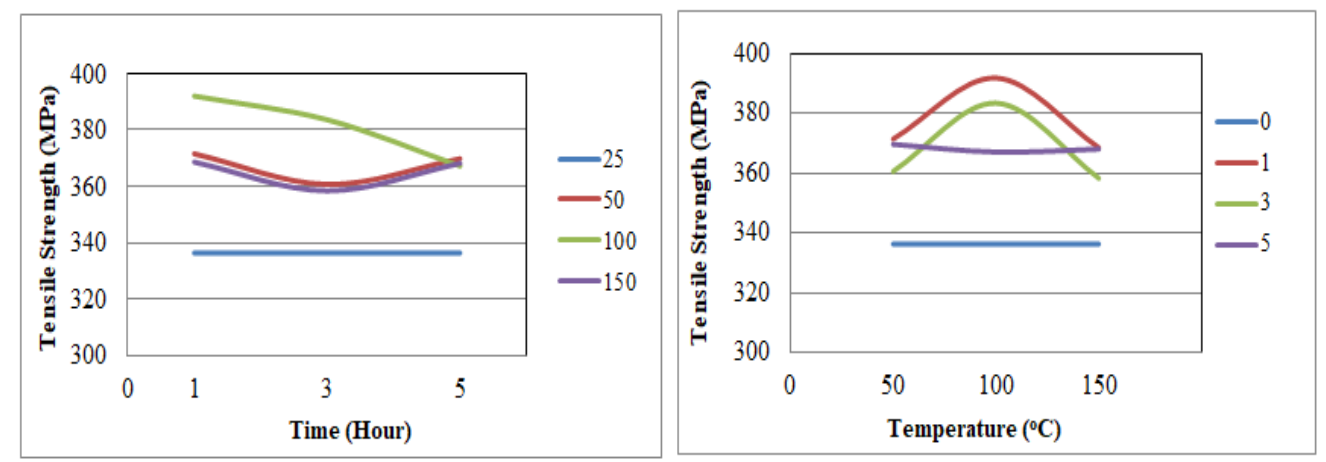

Figure 6. Graphs of tensile strengths obtained from thermally aged specimens based on time and temperature.

Shear strength values obtained from glass fiber reinforced epoxy composite specimens are shown in Figure 7 and Table 1. It is seen that maximum values are obtained from specimens exposed to thermal aging at $100{ }^{\circ} \mathrm{C}$. The shear strength values obtained from the specimens kept at $50{ }^{\circ} \mathrm{C}, 100{ }^{\circ} \mathrm{C}$ and 150 ${ }^{\circ} \mathrm{C}$ for 5 hours, respectively, according to the value obtained from the specimens kept at room temperature; $7.61 \%, 16.32 \%$ and $4.99 \%$ were found to be low. 
Table 1. Temperature-time effect on strength values obtained from specimens.

\begin{tabular}{|c|c|c|c|c|c|}
\hline \multirow{2}{*}{ 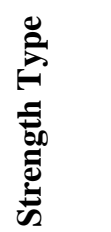 } & 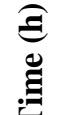 & \multicolumn{4}{|c|}{ Temperature parameters $\left({ }^{0} \mathrm{C}\right)$} \\
\hline & & 25 & 50 & 100 & 150 \\
\hline \multirow{3}{*}{ 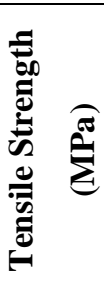 } & 1 & 336.4 & 371.5937 & 392.06 & 368.6633 \\
\hline & 3 & 336.4 & 360.7363 & 383.6367 & 358.43 \\
\hline & 5 & 336.4 & 369.8293 & 367.2233 & 368.2127 \\
\hline \multirow{3}{*}{ 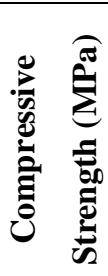 } & 1 & 250.815 & 202.2787 & 209.6153 & 171.2823 \\
\hline & 3 & 250.815 & 176.703 & 192.091 & 154.636 \\
\hline & 5 & 250.815 & 215.1523 & 229.8763 & 179.3153 \\
\hline \multirow{3}{*}{ 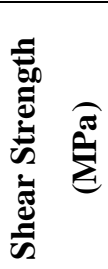 } & 1 & 80.8835 & 78.451 & 85.8115 & 74.72 \\
\hline & 3 & 80.8835 & 76.271 & 80.6225 & 67.6835 \\
\hline & 5 & 80.8835 & 84.434 & 95.9625 & 76.8405 \\
\hline
\end{tabular}
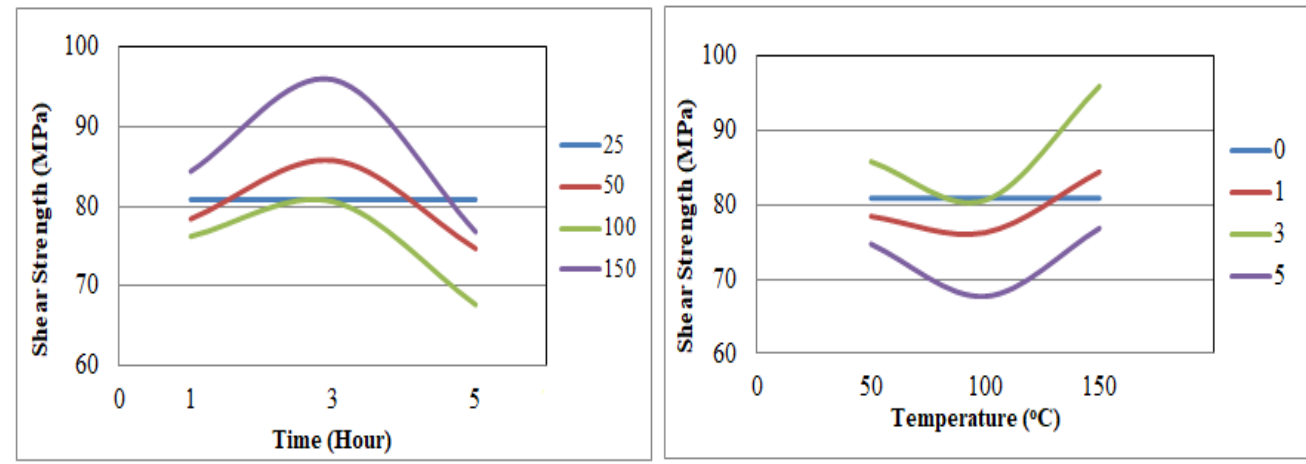

Figure 7. Graphs of shear strengths obtained from thermally aged specimens based on time and temperature.
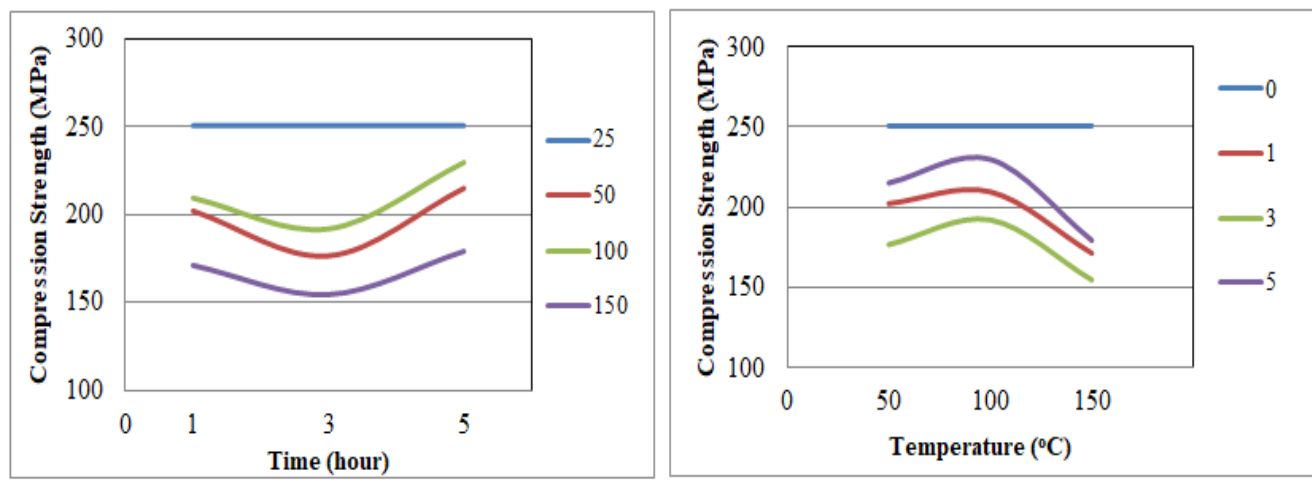

Figure 8. Graphs of compressive strengths obtained from thermally aged specimens based on time and temperature. 
The compressive strength of glass fiber reinforced epoxy composite specimens is shown in Figure 8 and Table 1. The highest compressive strength values were obtained from the specimens kept at room temperature $\left(25^{\circ} \mathrm{C}\right)$. Maximum values were obtained from specimens exposed to thermal aging at 100 ${ }^{\circ} \mathrm{C}$. The lowest values were obtained from the specimens subjected to thermal aging at $150{ }^{\circ} \mathrm{C}$ for 1 hour, 3 hours and 5 hours. According to the values obtained from the specimens at room temperature, it was calculated that they decreased by $31.70 \%, 38.70 \%$ and $28.50 \%$ respectively.

\subsection{The effect of thermal temperature on poisson ratio, elasticity and shear modulus and comparison}

The average values obtained in the determination of the modulus of elasticity of glass fiber reinforced epoxy composite specimens were transferred to Figure 9 and Table 2.
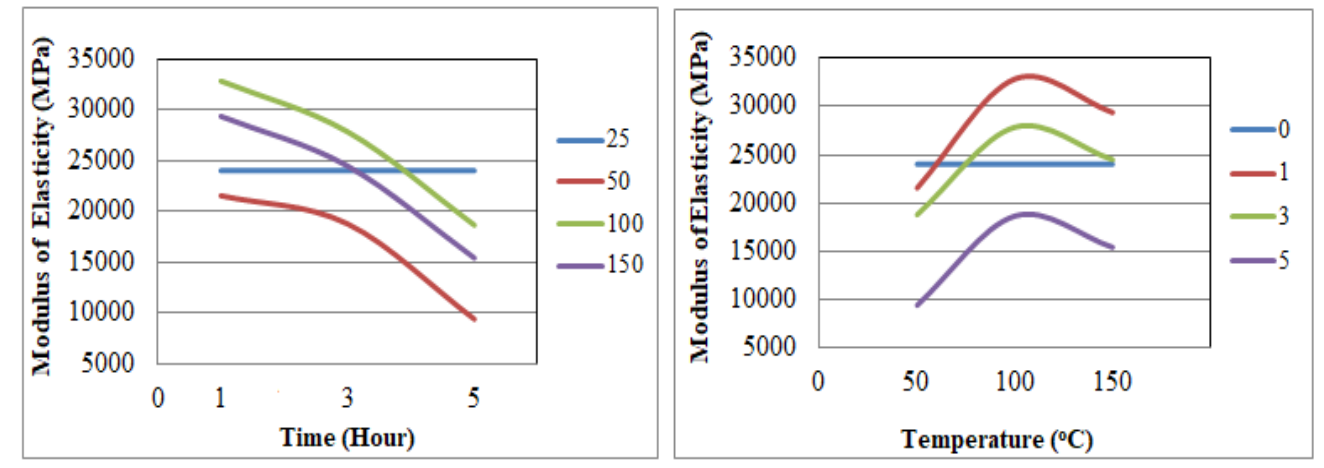

Figure 9. Graphs of Elasticity modulus obtained from thermally aged specimens based on time and temperature.

The highest elastic modulus value; it is obtained from specimens exposed to thermal aging at $100{ }^{\circ} \mathrm{C}$ for 1 hour. However, it was found that these values decreased when the waiting time was 5 hours. It was found that the elasticity modules obtained from the specimens kept at $50{ }^{\circ} \mathrm{C}, 100{ }^{\circ} \mathrm{C}$ and $150{ }^{\circ} \mathrm{C}$ decreased according to the values obtained from the specimens kept at room temperature $\left(25{ }^{\circ} \mathrm{C}\right)$ in the ratios of $\% 60.89, \% 22.32$ ve \%35.72, respectively (Figure 9, Table 2).
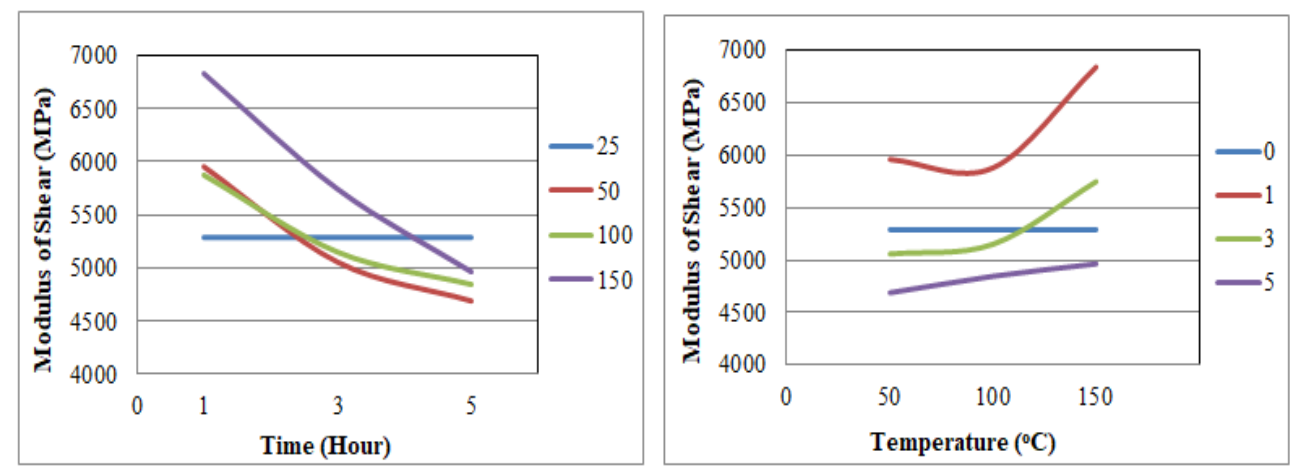

Figure 10. Graphs of Shear modulus obtained from thermally aged specimens based on time and temperature.

Shear modulus values of glass fiber reinforced epoxy composites were determined and indicated in Figure 10 and Table 2. The shear modulus values obtained when the specimens were exposed to thermal temperature for 1 hour at $50{ }^{\circ} \mathrm{C}, 100{ }^{\circ} \mathrm{C}$ and $150{ }^{\circ} \mathrm{C}$ increased compared with the values obtained from the specimens at room temperature; $12.62 \%, 11.13 \%, 29.21 \%$ respectively. This situation has a positive effect on the composite material, but it has been found that these values 
decrease when the waiting time increases. This situation; It also shows that the values obtained when kept at each temperature parameter for 5 hours decreased by $11,30 \%, 8,35 \%$ and $6,11 \%$, respectively, when compared to the values obtained from the specimens kept at room temperature (Figure 10).
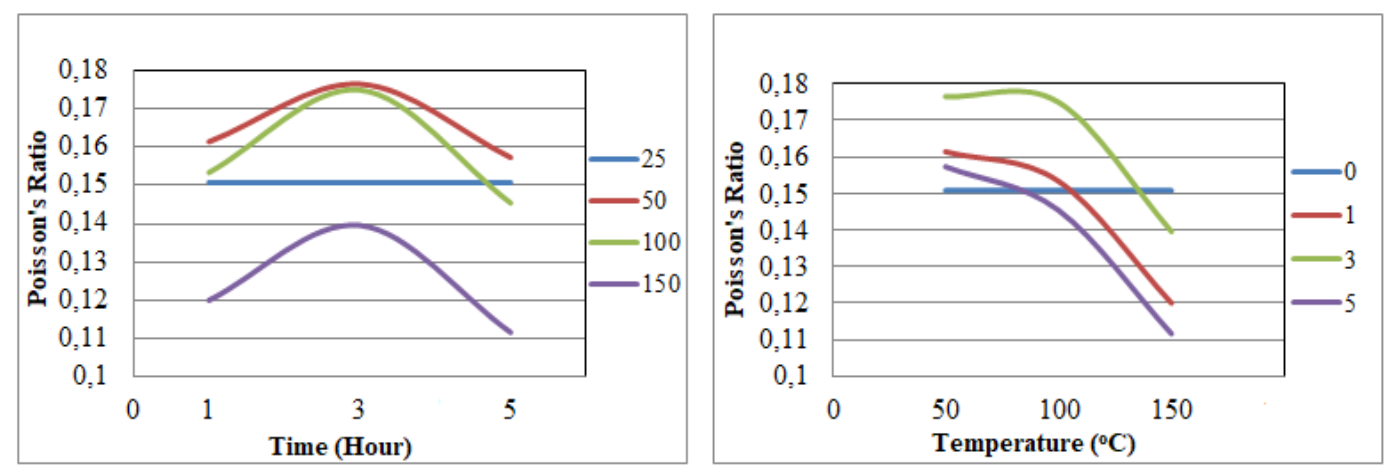

Figure 11. Graphs of Poisson's ratio obtained from thermally aged specimens based on time and temperature.

The values obtained after the test for determining Poisson's ratio were transferred to Figure 11 and Table 2. It is seen that the lowest poisson ratio values are obtained from the specimens aged at $150{ }^{\circ} \mathrm{C}$. At $50{ }^{\circ} \mathrm{C}$; poisson ratio increased between $6.7 \%-13.3 \%$, while the temperature at $150{ }^{\circ} \mathrm{C}$ caused a decrease between $13.33 \%-26.66 \%$.

Table 2. Temperature-time effect on the values obtained from the specimens

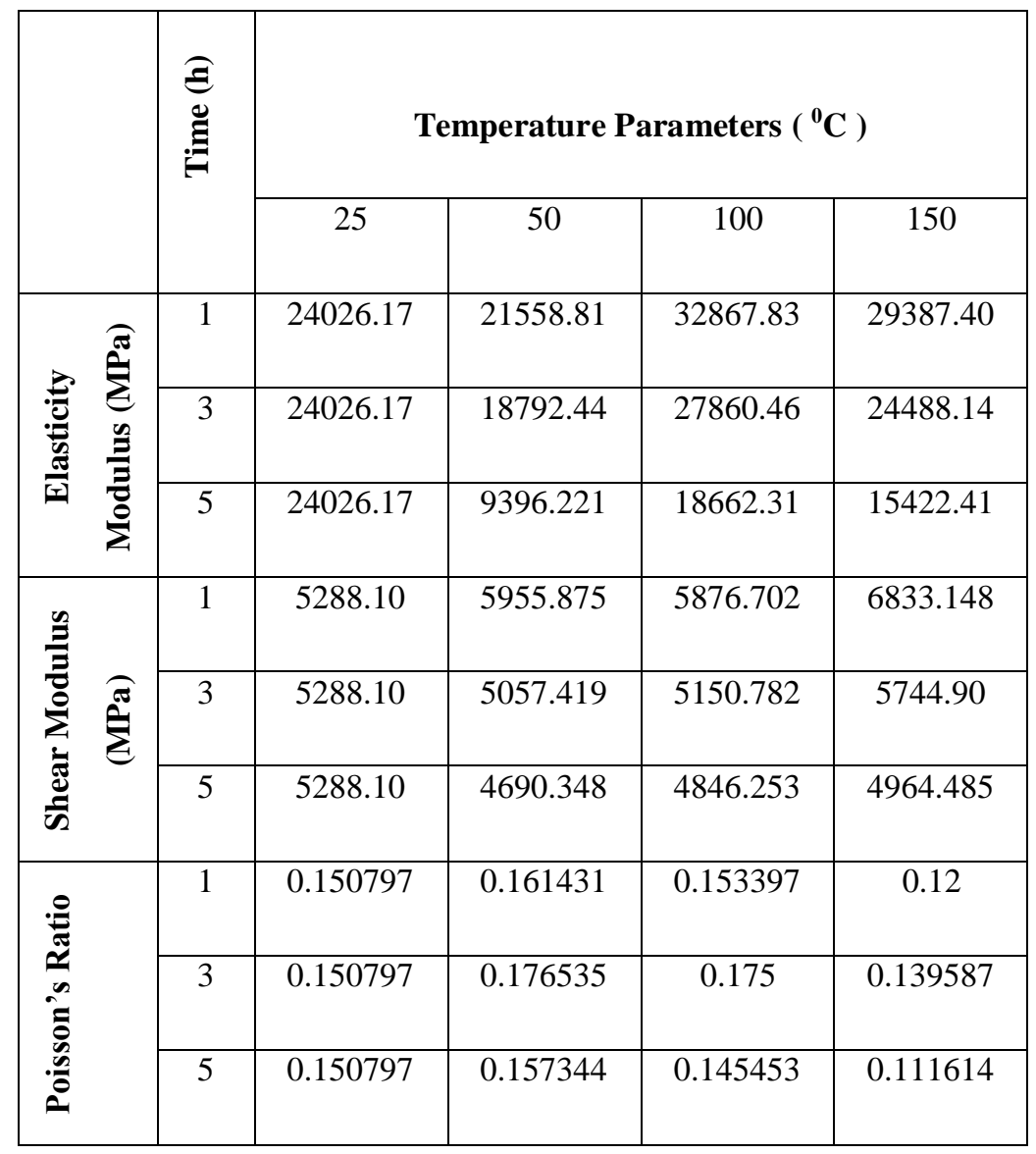




\subsection{Determination of the glass transition temperature of the composite plate}

The glass transition temperature of the glass fiber reinforced epoxy composite plate was determined by DSC tests to effectively understand thermal aging. Glass transition temperature tests were performed with Shimadzu DSC-60 device by increasing $10{ }^{\circ} \mathrm{C}$ every minute. As a result of the experiments, the glass transition temperature of the composite plate was found to be $107.95^{\circ} \mathrm{C}$ (Figure 12).

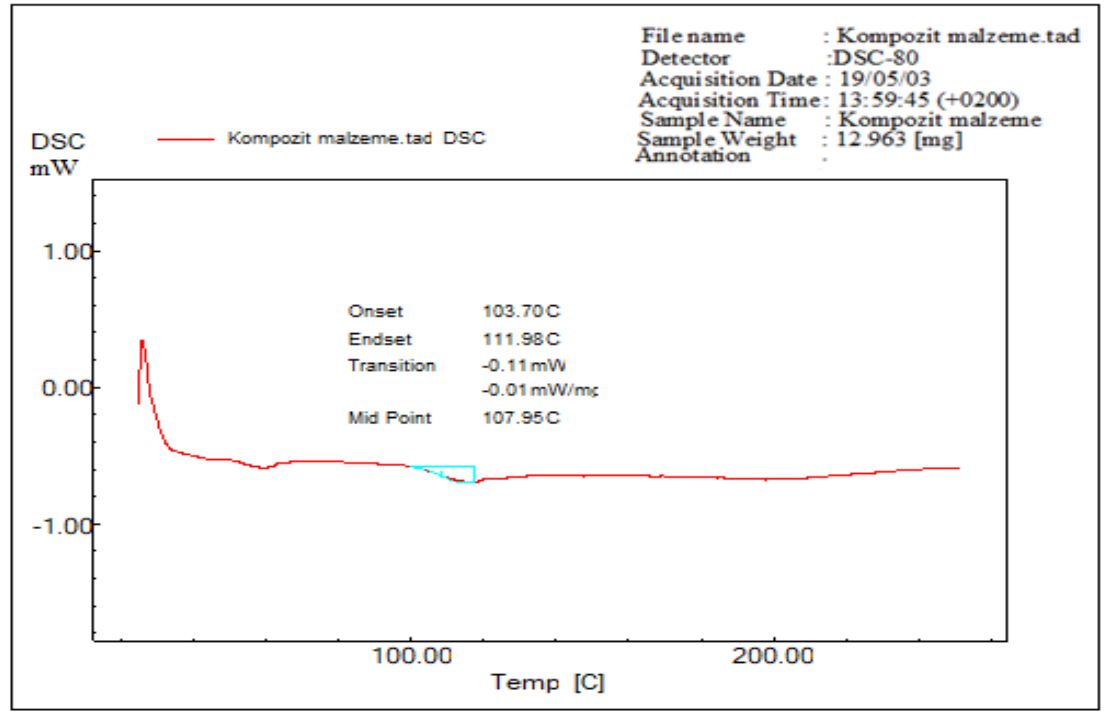

Figure 12. Graph of glass transition temperature of glass fiber reinforced woven epoxy composite plate.

\section{Results}

The values obtained in the study re-demonstrated the importance of the relationship between temperature and composite plates. Because it is known that if the glass transition temperature of the glass fiber reinforced epoxy composite plate is exceeded, the fiber-resin interfaces of the composites will deteriorate and consequently their strength is expected to decrease. The damage to the integrity of the matrix material [15] appears to be more pronounced above the glass transition temperature of the composites. It also increases the viscosity of polymers when the temperature exceeds the glass transition temperature. In this meaning, the glass transition temperature is a critical threshold [11]. However, in the experiment, it has been found that with the increase of temperature, it causes an increase in tensile strength, even if it is low, and other mechanical properties decrease.

In this study, it was determined that the tensile strength of the composite increased by $6.55 \%$ and $16.5 \%$, especially with the increase of thermal temperature. It is seen that the composite specimen reaches the maximum value at $100{ }^{\circ} \mathrm{C}$ at the value close to the glass transition temperature. It was observed that the maximum values obtained at $150{ }^{\circ} \mathrm{C}$ were decreased /steady progress when $\mathrm{Tg}$ temperature was exceeded. This progress is noted in the study by Cao et al. [12] and Plecnik [17]. In addition, Sauder et al. reported that they reached maximum strength value with increasing temperature due to fiber texture [13]. If the temperature exceeds $150{ }^{\circ} \mathrm{C}$, these values are expected to decrease further. In addition, an increase was observed in shear strength (5 hours at $50^{\circ} \mathrm{C}, 1-5$ hours at $\left.100{ }^{\circ} \mathrm{C}\right)$, poisson ratio $\left(1.3,5\right.$ hours at $\left.50{ }^{\circ} \mathrm{C}\right)$, elasticity $\left(1\right.$ to 3 hours at $100{ }^{\circ} \mathrm{C}$ to $\left.150{ }^{\circ} \mathrm{C}\right)$ and shear modulus ( 1 hour at 50,100 and $150{ }^{\circ} \mathrm{C}$ ) values. However, it was found that these values decreased when waiting time and temperature increased. As can be seen in the literature $[10,11,12,14,18]$. 


\section{Conclusions}

In this study, the effects of thermal temperature on the glass fiber reinforced epoxy composite plate were investigated experimentally. Specimens were kept at $50{ }^{\circ} \mathrm{C}, 100{ }^{\circ} \mathrm{C}$ and $150{ }^{\circ} \mathrm{C}$ for 1,3 and 5 hours. Then tensile test was performed and the results were evaluated.

As a result of this experimental study;

- It was found that the compressive strength values of the specimens exposed to thermal aging were lower.

- The lowest values of modulus of elasticity, poisson ratio, shear modulus and shear strength were obtained from the specimens kept at $150^{\circ} \mathrm{C}$ for 5 hours.

- It was found that mechanical properties of the specimens decreased with increasing temperature and waiting time except tensile strength.

\section{Acknowledgment}

This work, it was supported by DÜBAP ENGINEERING-15.010 project.

\section{References}

[1] Mouzakis, D.E., Zoga, H., Galiotis, C., Accelerated Environmental Ageing Study of Polyester/Glass Fiber Reinforced Composites (GFRPCs), Composites: Part B, 39 (2008),pp. $467-$ 475.

[2] Leveque, D., Schieffer, A., Mavel, A., Maire, J.F., Analysis of How Thermal Aging Affects The Long-Term Mechanical Behavior and Strength of Polymer-Matrix Composites, Composites Science and Technology ,65 (2005), pp.395-401.

[3] Tsotsis, T.K., Keller, S., Lee ,K., Bardis, J., Bish J., Aging of Polymeric Composite Specimens for 5000 Hours at Elevated Pressure and Temperature, Composites Science and Technology, 61 (2001), pp. 75-86.

[4] Muliana, A., Nair, A., Khan, KL.A., Wagner, S., Characterization of Thermo-Mechanical and Long-Term Behaviors of Multi-Layered Composite Materials, Composites Science and Technology, 66 (2006),pp. 2907-2924.

[5] Alcock, B., Cabrera, N.O., Barkoula, N.M., Reynolds, C.T., Govaert, L.E., Peijs, T., The Effect of Temperature and Strain Rate on the Mechanical Properties of Highly Oriented Polypropylene Tapes and All-Polypropylene Composites, Composites Science and Technology, 67 (2007), pp. 2061-2070.

[6] Brinson, L.C., Gates, T.S., Effects of Physical Aging on Long Term Creep of Polymers and Polymer Matrix Composites , Inf. J. Solids Structures, 32( 1995 ), pp. 827-846.

[7] Dlouhy, I., Chlup, Z., Boccaccini, D.N., Atiq, S., Boccaccini, A.R., Fracture Behaviour of Hybrid Glass Matrix Composites: Thermal Ageing Effects, Composites: Part A, 34 (2003), pp.1177-1185.

[8] Ray, B.C., Thermal Shock on Interfacial Adhesion of Thermally Conditioned Glass Fiber/Epoxy Composites, Materials Letters, 58 (2004), pp.2175-2177. 
[9] Hu, H., Sun, C.T., The Characterization of Physical Aging in Polymeric Composites, Composites Science and Technology , 60 (2000), pp. 2693-2698.

[10] Belaid, S., Chabira, S.F., Balland, S.P., Sebaa, M., Belhouideg, S., Thermal Aging Effect on The Mechanical Properties of Polyester Fiberglas Composites, J. Mater. Environ. Sci., 6 (2015) ,10, pp. $2795-2803$

[11] Cao, S., Wu, Z., Wang, X., Tensile Properties of CFRP and Hybrid FRP Composites at Elevated Tempertures, Journal of composite materials,43(2009), 4.

[12] Cao, S., Wu, Z., Tensile Properties of FRP Composites at Elevated and High Temperatures, Journal of applied mechanics , 11(2008),pp. 963-970.

[13] Sauder, C., Lamon, J., Paille, R., The Tensile Behavior of Carbon Fibers at High Temperatures up to $2400{ }^{\circ} \mathrm{C}$, Carbon, 42 (2004),pp. $715-725$.

[14] Nikolaev, V.P., Myshenkova, E.V., Pichugin, V.S., Sinitsyn, E.N., Khoroshev,A. N., Temperature Effect on the Mechanical Properties of Composite Materials, Inorganic Materials, 50(2014), 15, pp. 1511-1513.

[15] Giannadakis, K.,Varna, J., (2009). Effect of Thermal Aging and Fatigue on Failure Resistance of Aerospace Composite Materials, IOP Conf. Series: Materials Science and Engineering, 5, doi:10.1088/1757-899X/5/1/012020.

[16] Eric, A., Carelli, V., Effects of Thermal Aging on the Mechanical Properties of a Porous-Matrix Ceramic Composite, J. Am. Ceram. Soc., 85(2002), 3, pp.595-602.

[17] Plecnik, J., Temperature Effects on Epoxy Adhesives, Journal of Structural Division, 106 (1980), 106(1), pp. 99-113.

[18] Rami, A. H., Adi, A.O., Jamal, A. A., Adil A.T., Temperature Effect on the Mechanical Properties of Carbon, Glass and Carbon-Glass FRP Laminates, Construction and Building Materials , 75 (2015), pp. 342-348.

[19] Carlsson, L.A, Pipes, R.B., Experimental Characterization of Advanced Composite MaterialsSecond Edition, Technomic Publishing Company book,(1997).

[20] Okutan, B., Stress and Failure Analysis of Laminated Composite Pinned Joints, Ph. D. thesis, Science Institute of Dokuz Eylül University, İzmir. 2001. 